\title{
Trends, patterns, and incidence rate of seasonal influenza among Dubai population and some associated factors, 2017-2-19
}

\author{
M. Ibrahim Gamal, Hamid Y. Hussain*, Wafa K. Alnakhi, Heba Mamdouh
}

Dubai Health authority, Strategy and corporate development sector, research- study and data analysis Dept, Dubai, UAE.

*Corresponding Author: Hamid Yahya Hussain, Dubai Health authority, Strategy and corporate development sector, research- study and data analysis Dept, Dubai, UAE.

Received date: January 21, 2020; Accepted date: April 09, 2021; Published date: April 13, 2021

Citation: M. Ibrahim Gamal, Hamid Y. Hussain, Wafa K. Alnakhi, H Mamdouh. (2021) Trends, patterns, and incidence rate of seasonal influenza among Dubai population and some associated factors, 2017-2-19. International Journal of Clinical Case Reports and Reviews. 7(1); DOI: $10.31579 / 2690-4861 / 109$

Copyright: (C) 2021 Hamid Yahya Hussain, This is an open-access article distributed under the terms of the Creative Commons Attribution License, which permits unrestricted use, distribution, and reproduction in any medium, provided the original author and source are credited.

\section{Abstract:}

Background: WHO estimates that seasonal influenza may result in 290 000-650 000 deaths each year due to respiratory diseases alone. In addition, affected more than $10 \%$ of total population annually worldwide, Seasonal influenza is highly contagious disease; spreads easily, with rapid transmission in crowded areas including schools and nursing homes.

Objectives: To Study incidence rate, trends and patterns of seasonal influenza among Dubai population for the period 2017 2019 , to Study some of the associated factors.

Materials \& Subjects: A retrospective records review study was carried out of convenience sample of 29158 confirmed seasonal influenza case reported in Emirate of Dubai for the period 2017-2019. All age groups, genders, nationalities, occupations, education and seasons were considered.

Findings: The study showed that $53.42 \%$ of total seasonal influenza cases were among male groups in Dubai, almost $50 \% \%$ of the cases were among age group less than 15 years old, and almost one quarter of cases were among the age group between 30-40 years old, the present study showed that $54.37 \%$ were among Asian groups, $14.59 \%$ of the seasonal influenza incidence in Dubai during 2017-2019 were among Emirati population and 18.79\% were among Arabs groups .As per occupation, the study showed that $30.74 \%$ of total seasonal influenza cases were among students in Dubai, on the other hand the study revealed that $84.53 \%$ of the total seasonal influenza cases during $2017-2019$ were handled at outpatient level, yet $15.47 \%$ were sever enough cases to be admitted and treated at inpatient facilities. Incidence rate per 100000 population were increased respectively from 2017 through out $2019(168,297,466)$. The study revealed as well that the rate as per nationality the seasonal influenza incidence rate in Dubai from 2017=2019 650/100000 among Jordanian living in Dubai,, almost $50 \% \%$ of the cases were among age group less than 15 years old, and almost one quarter of cases were among the age group between $30-40$ years old, the present study showed that $54.37 \%$ were among Asian groups, $14.59 \%$ of the seasonal influenza incidence in Dubai during 2017-2019 were among Emirati population and 19.71\% were among Arabs groups .

The study showed that $30.74 \%$ of total seasonal influenza were students in Dubai, $84.53 \%$ of the total seasonal influenza cases during 2017-2019 were managed at outpatient. yet $15.47 \%$ were sever enough cases to be admitted and treated at inpatient level of different health care facilities in Dubai. Incidence among Egyptian was 557/100000, while among Emirates, $325 / 100000$, Incidence rate of seasonal influenza 2017-2019 according to age distributions showed that $30.7 \%$ among students, and $7.8 \%$ among children preschool age, and 5.22\%among housewives. The present study showed that the incidence rate of seasonal influenza in Dubai in 2017-2019 as per moth distributions was the highest, $21.4 \%$ in November followed by $18.2 \%$ in December, and the least was $2 \%$ in July

Conclusions: incidence rate of seasonal influenza in Dubai keep increasing during the last three years, the highest rates significantly come from children segment of population specially students and elderly group as well, the period from October to end of February of each years.

Keywords: seasonal influenza; patterns; incidence rate; dubai population; associated factors 


\section{Introduction:}

Seasonal influenza is highly contagious disease; easily and rapidly spreads, with high transmission rate in places with overcrowding and high population density. During last few years some figures reported about increasing of influenza incidence in Emirate of Dubai which needs to be carefully inspected and interpreted for policy decision making, and system intervention containment strategy. Influenzas are remarkable threat at global health function, almost affects every single country annually. WHO talked 1 billion incidence case globally at annual base, about 3-5 million cases with complications, hospital admissions and significant care utilization, the international figures telling of (290000650000)-death event related to influenza- respiratory complications worldwide. Since three years back, world health organization prepared plan to raise awareness of national health systems for potential influenza pandemic outbreak, stressed on a fact a pandemic wave is few steps far from the door [1].

World health organization lunched framework of Global strategy initiative on seasonal influenza for 2019-2030, multiple countries and technical partners were enrolled, to proposing containing efforts to foreseen threatens. Comprehensive multi-dimensional and inter sectoral by means of vigorous national actions at level of surveillance, laboratory capacity development, public health measures and clinical management through addressing and filling gaps to achieve optimum prevention and control level. The goal targeted goals remains as of strengthening seasonal control, preventions and preparedness for anticipated pandemics. In order to reaching similar target, necessities to developing global and national containment strategies, which places a large focus on the following: vaccines, as global tool strategy to be in the core of developmental steps, treatments by antiviral agents to benefit most of the countries and build public confidence, and investing in technical capacity uptake; of Stronger and integrated health functions inside universal health coverage efforts and national health security planning [2].

According to Centre for Diseases control and preventions (CDC), it has been estimated that annual influenza cases in United states of America has reached up to ( 9 million -45 million illnesses), out of which, between $(140,000-810,000)$ cases were admitted to hospitals every year and the account of death was $(12,000-61,000)$ event yearly since the year of 2010.[3]. World Health organization reported that, seasonal influenza cause (290000-650000) deaths event annually because of to acute respiratory illnesses (ARI) and its consequences. Gaps still remain such as a lack of high quality and up-to-date estimates of severe influenza burden at global and regional levels, despite an increase in the number of countries investing extensively to inform prevention measures of influenza,; Somehow few numbers of middle and low -income countries (LMICs), managed to develop trustable national accounts of seasonal influenza (BoD burden of disease). The lack of reliable Burden of diseases data as well as the potential effect of vaccination among specific high-risk groups. Highlighting the scale of the influenza threats at regional, national and global level shall re-enforces the need for nations to take action to address their influenza disease burden. [4]

Seasonal influenza International studies showed that in UK, Influenza was responsible for an estimated 145000 deaths among all ages in 2017. The influenza LRTI mortality rate was highest among adults older than 70 years16•4 deaths per 100000 [95\% UI 11•6-21•9]) [5], while Saudi Arabia was H1N1 given an incidence rate of 3.5 per 1000. [6].

In UAE studies reported that influenza was the most frequently detected virus (273/1362 [20.0\%]), followed by human rhinovirus (146/1362 [10.7\%]). The influenza positivity rate showed two peaks, which occurred in August and December [7].
It the context of Covid19 pandemic, the situation become more complicated, the burdens and damages made by covid 18 at health $\mathrm{m}$ social and economic level .

\section{The current study is aiming at:}

To Study incidence rate, trends and patterns of seasonal influenza among Dubai population for the period 2017-2019. Top Study some of the associated factors.

\section{Material and Methods:}

A retrospective records review study was conducted on convenience sample of 29158 confirmed seasonal influenza case reported in Emirate of Dubai for the period (2017-2019). Secondary reported data was retained from private sector facilities in Dubai, All age groups, genders, nationalities, occupations, education and seasons were considered. Operational definition of confirmed seasonal influenza was adopted as laboratory diagnosis of influenza Virus (A \& or B by PCR test and treated clinically as a case of seasonal influenza inpatient or outpatient clinic.

Exclusion and inclusion criteria was applied (all laboratory confirmed cases were included in the study), repeated cases within three months as infected again were excluded) the data sheet were excluded, a cases with inadequate information or unconfirmed diagnoses were all excluded from the recruitment process.

Data coding, entry, cleaning and data analysis was carried by using statistical package soft were SPPS21,.and R studio 95\% level of significance and). $05 \mathrm{P}$ value was adopted.

\section{Results:}

The current study showed that $53.42 \%$ of total seasonal influenza cases were among male groups in Dubai, almost $50 \% \%$ of the cases were among age group less than 15 years old, and almost one quarter of cases were among the age group between 30-40 years old, the present study showed that $54.37 \%$ were among Asian groups, $14.59 \%$ of the seasonal influenza incidence in Dubai during 2017-2019 were among Emirati population and $18.79 \%$ were among Arabs groups.

As per occupation, the study showed that $30.74 \%$ of total seasonal influenza cases were among students in Dubai, on the other hand the study revealed that $84.53 \%$ of the total seasonal influenza cases during 2017 2019 were handled at outpatient level, yet $15.47 \%$ were sever enough cases to be admitted and treated at inpatient level of different health care facilities in Dubai. As shown by table (1) The present study revealed that incidence rate per 100000 population were increased respectively from 2017 through out $2019(168,297,466)$ as shown by figure (1), The study reflected that the incidence rate by age groups, the highest in the age group $2-5$ years old $23.5 / 100000$, age group $1-2$ years $18.68 \%$, and the age group $30-35$ years old $9.1 \%$. In addition, the least rate was among 55 years old, $0.99 / 100000$.as shown in figure (2). The study revealed as well that the rate as per nationality the seasonal influenza) $14.59 \%$ among Emirati, 19.71\% among other Arabs and 54.37\% among Asian

Incidence rate of seasonal influenza in Dubai for the period 2017-2019 according to age distributions showed that $30.7 \%$ among students, and $7.8 \%$ among children preschool age, and 5.22\%among housewives is as shown by table(1). The present study showed that the incidence rate of seasonal influenza in Dubai in 2017-2019 as per moth distributions was the highest, $21.4 \%$ in November followed by $18.2 \%$ in December, and the least was $2 \%$ in July. The study found that total cases of seasonal influenza infection in Dubai for the period 2017-2019 as per year quartile showed that quarter one (Q1) showed 8845 cases, quarter two (Q2) revealed 3195 cases, quarter three (Q3) showed 2254 and quarter four (Q4) showed 14564 case as shown in figure (5). 


\begin{tabular}{|c|c|c|c|c|c|c|}
\hline \multirow{2}{*}{ Variables } & \multirow{2}{*}{ Factors } & \multicolumn{3}{|c|}{ Year } & \multirow{2}{*}{ Total } & \multirow{2}{*}{$\begin{array}{c}\text { Total } \\
\text { percentage }\end{array}$} \\
\hline & & 2017 & 2018 & 2019 & & \\
\hline \multirow{2}{*}{ Sex } & Female & 2,230 & 4,221 & 7,132 & 13,583 & 46.58 \\
\hline & Male & 2,535 & 4,931 & 8,109 & 15,575 & 53.42 \\
\hline \multirow{4}{*}{ Nationality } & Citizen & 648 & 1,439 & 2,166 & 4,253 & 14.59 \\
\hline & Other Arabs & 1,005 & 1,781 & 2,961 & 5,747 & 19.71 \\
\hline & Asian & 2,673 & $4,4,886$ & 8,293 & 15,852 & 54.37 \\
\hline & Other & 439 & 1,046 & 1,821 & 3,306 & 11.34 \\
\hline \multirow{8}{*}{ Age group } & Less than $5 \mathrm{y}$. & 1,483 & 2,541 & 3,599 & 7,623 & 37.17 \\
\hline & $5-$ & 1,128 & 2,089 & 3,635 & 6,852 & 33.41 \\
\hline & $10-$ & 481 & 1,021 & 2,225 & 3,727 & 18.17 \\
\hline & $20-$ & 311 & 6993 & 1,304 & 2,308 & 11.25 \\
\hline & $30-$ & 797 & 1,579 & 2,735 & 5,111 & 24.92 \\
\hline & (40- & 350 & 754 & 1,133 & 2,237 & 10.91 \\
\hline & $50-$ & 140 & 280 & 349 & 769 & 3.75 \\
\hline & $60+$ & 75 & 195 & 261 & 531 & 2.59 \\
\hline \multirow{6}{*}{ Occupations } & Student & 1,385 & 2,791 & 4,787 & 8,963 & 30.74 \\
\hline & $\begin{array}{l}\text { Undefined } \\
\text { profession }\end{array}$ & 1,424 & 2,562 & 4,266 & 8,252 & 28.30 \\
\hline & $\begin{array}{l}\text { Child (Non } \\
\text { 'Student) }\end{array}$ & 373 & 722 & 1,192 & 2,287 & 7.84 \\
\hline & "House wife & 247 & 438 & 838 & 1,523 & 5.22 \\
\hline & Officer Work & 385 & 712 & 1,176 & 2,273 & 7.80 \\
\hline & $\begin{array}{l}\text { Other } 740 \\
\text { occupations }\end{array}$ & 951 & 1,927 & 2,982 & 5,860 & 20.10 \\
\hline \multirow{4}{*}{ Month } & $\mathrm{Q1}$ & 1,428 & 2,721 & 4,696 & 8,845 & 30.33 \\
\hline & Q2 & 546 & 1,009 & 1,640 & 3,195 & 10.96 \\
\hline & $\overline{\mathrm{Q} 3}$ & 434 & 824 & $1,1,296$ & 2,554 & 8.76 \\
\hline & $\mathrm{Q} 4$ & 2,357 & 4,598 & 7,609 & 14,564 & 49.95 \\
\hline \multirow{2}{*}{$\begin{array}{c}\text { The section } \\
\text { where he was } \\
\text { treated }\end{array}$} & Outpatient & 4,001 & 7,740 & 12,906 & 24,647 & 84.53 \\
\hline & In-patient & 764 & 1,412 & 2,335 & 4,511 & 15.47 \\
\hline \multicolumn{2}{|c|}{ Total } & 4,765 & 9,152 & 15,241 & 29,158 & 100.00 \\
\hline
\end{tabular}

Table 1: Socio-demographic charechertstics of seasonal Influenza among Dubai population 2017-2019

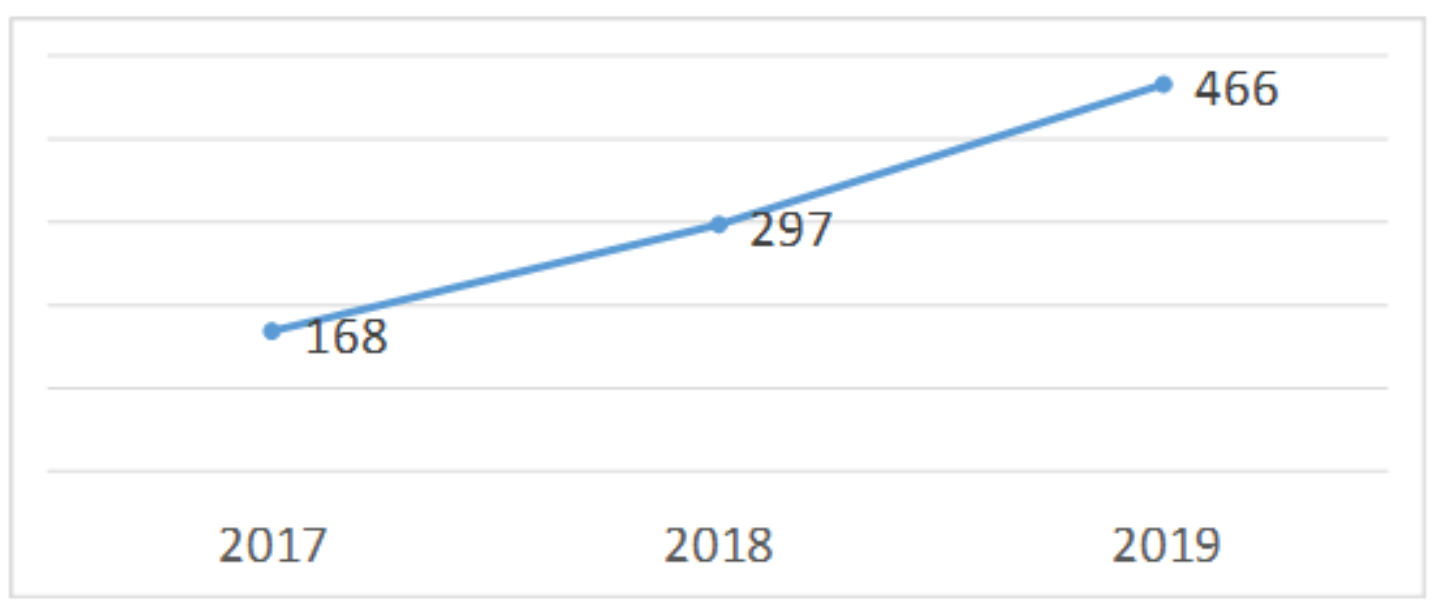




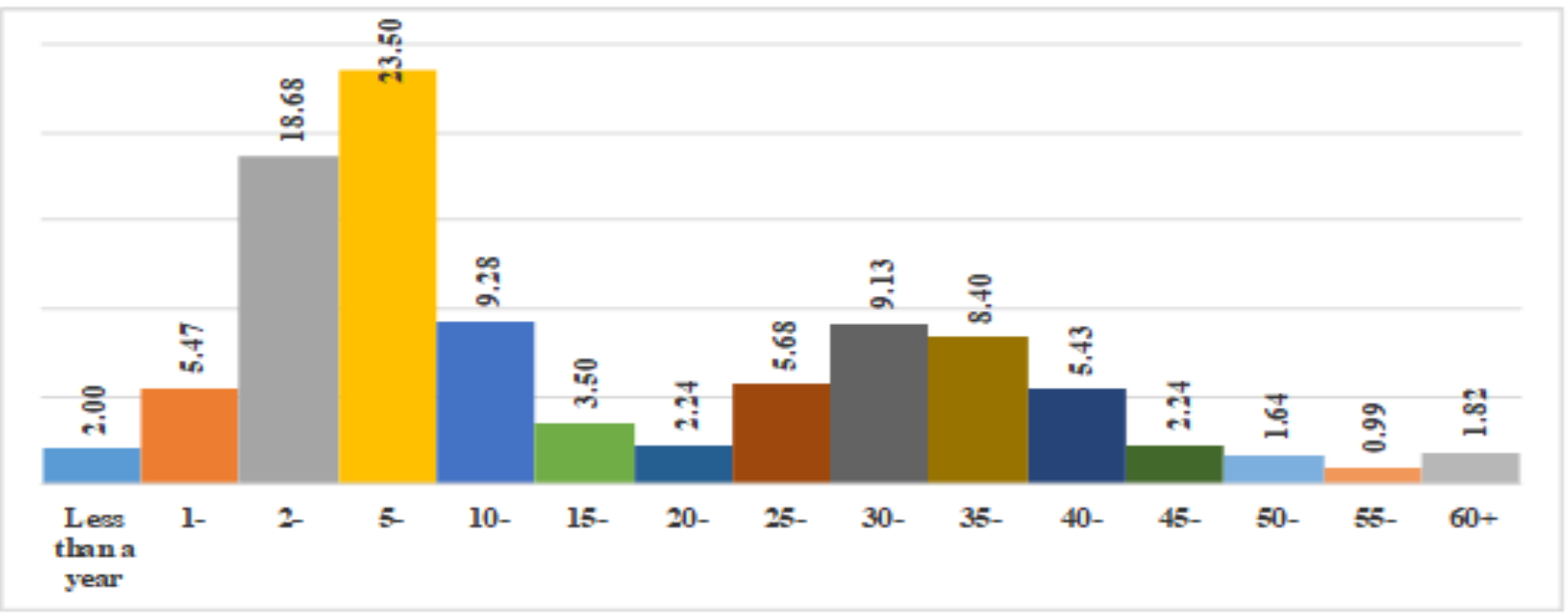

Figure 2: Age distribution of seasonal influenza incidence rate Among Dubai Population 2017-2019

\begin{tabular}{|c|c|c|c|c|}
\hline \multirow{2}{*}{\multicolumn{2}{|c|}{ Age indicators of infected people }} & \multicolumn{3}{|c|}{ Year } \\
\hline & & \multirow{2}{*}{$\begin{array}{l}2017 \\
17.39\end{array}$} & \multirow{2}{*}{2018} & \multirow{2}{*}{2019} \\
\hline Mean & & & & \\
\hline \multirow{2}{*}{$\begin{array}{l}\text { 95\% Confidence Interval } \\
\text { for Mean }\end{array}$} & Lower Bound & 16.91 & 18.33 & 18.29 \\
\hline & Upper Bound & 17.88 & 19.04 & 18.81 \\
\hline Median & & 8.27 & 9.76 & 10.79 \\
\hline Minimum & & 0.09 & 0.07 & 0.06 \\
\hline "Maximum & & 88.5 & 90.5 & 92.62 \\
\hline
\end{tabular}

Table 2: Statistical values around Seasonal influenza patients ages 2017-2019

\begin{tabular}{|c|c|c|}
\hline Nationalities & Average incidence in 3 years & Infection rate per 100,000 population \\
\hline Citizen & 1418 & 557 \\
\hline Other Arabs & 1354 & 2039 \\
\hline Asian & 5007 & 1116 \\
\hline Other & 160 & 257 \\
\hline
\end{tabular}

Table 3: Seasonal influenza incidence rate per 100000 of population According to nationalities in Dubai 2017-2019

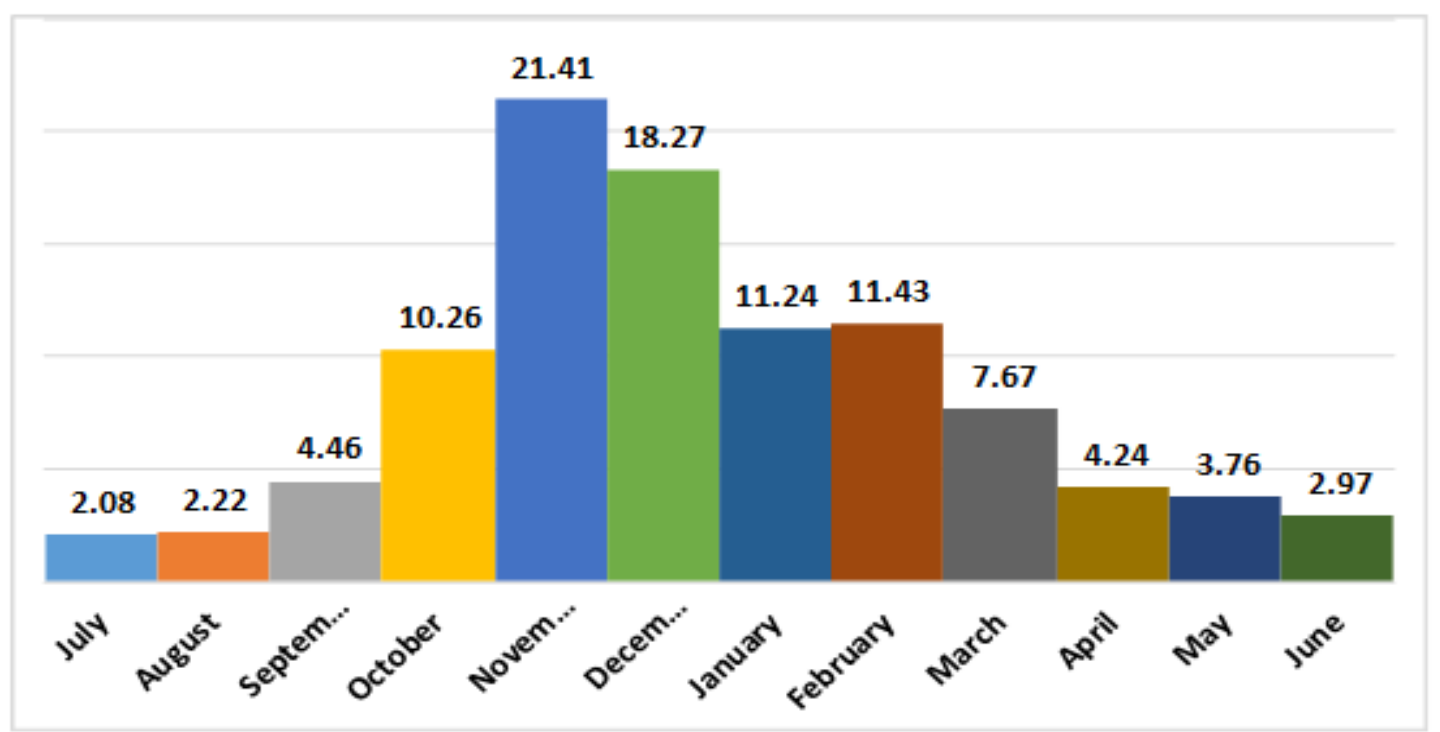




\section{Discussions:}

The current study showed that the incidence rate of seasonal influenza incidence rate among Dubai population in 2019 was 466 case per100000 population, more among male comparing to females and highest in December. This finding is similar to the other studies finding in Saudi Arabia [5, 6, 7] which revealed that, $733(53.8 \%)$ male and $629(46.2 \%)$ female patients with ARI who visited the health care centers between November 2015 and February 2018. The -PCR test revealed an overall positivity rate of $37.2 \%$ (507/1362). The positive rate increased during winter; it was highest in December and lowest in September.

Other studies finding regarding seasonality of the diseases found to be in agreement with current study findings $[8,9,10]$, which revealed that similar seasonality pattern on respiratory viral infection rates was observed in our study. Influenza was the main contributing organism to the seasonal pattern; the subtypes A/H1N1/pdm09 and influenza B contributed predominantly to the winter peak. Low temperatures and low specific humidity during the winter season in the UAE may be the cause of the peak in the number of influenza like illnesses in the winter. In addition to the major peak in the winter, a small peak in August was also observed for influenza (semi-seasonal pattern), which parallels the patterns reported from temperate and tropical countries in the Northern Hemisphere.

The current study conclude similar results comparing to other studies carried out in Egypt, Jordan, Oman and yamen [ 11 ], regarding seasonal influenza rate by age. The available data showed that, the majority of the cases $(96 \%)$ were under 5 years of age. The highest incidence among younger age group concluded in this study was similarly found in other study in china, yet in china study found that the incidence rate was among the highest rates in all age groups. Such finding can be explain by lack of preventive and hygienic precautions by younger age groups from one side and from other sides low and less maturity of immune system in young age groups [12].

As the current study Reflected that ethnicity groups showed different incidence rate, this finding could come with explanation that ethnicity may be linked to individuals and groups behaviors as well as some genetic element which can put some ethnicities at high risk of exposure, this finding was found to be similar to the other studies finding that revealed influenza transmission is constrained by contact patterns, which are influenced by individual behavior and sociological events. For example, the closing of schools for the two-week Holy Week period likely hampered the early transmission of H1N1/09 in Mexico City and the subsequent implementation of social distancing interventions including school closures. These events prevented contacts that typically take place within schools that are thought to be pivotal to spread of flu through communities. The reverse is also true: the dynamics of infectious diseases can dramatically alter the structure of a host population $[13,14,15$, and $16]$.

\section{- $\quad$ Study Limitations:}

- The data utilized was mainly driven from private sector statistics, as public sector reporting was inadequate.

- Behavioral risk factors related to spreading of seasonal influenza were not well addressed due to being secondary accumulated data gathered for statistical documentation peruses.

- $\quad$ Lack of full information specially that one related to clinical lay out of the cases.

\section{- Study strengths:}

The study sample was big enough to obtain good conclusions.
Future research will be of great benefits on seasonal influenza in Dubai if focusing on:

in Dubai

Clinical outcome and complications rates of seasonal influenza

Morbidities and mortalities among High risk groups in Dubai.

Gaps in Vaccination coverages

\section{Conclusions:}

The current study concluded that, the incidence rate of seasonal influenza in Dubai keep increasing during the last three years, yet the annual increment is not alarming, the highest rates significantly come from children segment of population specially students and elderly group as well, the period from October to end of February of each years showed the highest rate of seasonal influenza incidence.

\section{Policy implications}

Gaps in preventions like promoting healthy behaviors, bridging vaccination coverage gaps, focusing on high risky groups, strengthening influenza surveillance program and improving public health response measures.

\section{Ethical issues:}

Ethical standard procedures we applied to the best of possible throughout all stages of the research

\section{Conflict of Interests:}

All authors declared that there are no conflict of interest.

\section{References:}

1. WHO release 2018 (influenza seasonal) ask expert.

2. WHO Report, Global influenza strategy (Surveillance efforts).

3. CDC report 2019 (influenza Burden in USA).

4. WHO release Influenza Burden.

5. Mortality, morbidity, and hospitalizations due to influenza lower respiratory tract infections UK Report, 2017: an analysis for the Global Burden of Disease Study 2017.

6. Hatem K. Herzallah, MD, ScD, Salah A. Bubshait, (Epidemiology), Amalraj K. Antony. (2011) Incidence of influenza A H1N1 2009 infection in Eastern Saudi Arabian hospitals. Saudi Med J; 32(6).

7. Jae-Hyun Jeon, Minje Han, Ho-Eun Chang, Sung-Soo Park, Jae-Woong Lee, Young-Joon Ahn,Duck-Jin Hong. (2019) Incidence and seasonality of respiratory viruses causing acute respiratory infections in the Northern United Arab Emirates, journal of medical virology. 91(8); 1378-1384.

8. Morikawa S, Kohdera U, Hosaka T, et al. (2015) Seasonal variations of respiratory viruses and etiology of human rhinovirus infection in children. J Clin Virol. 73: 14-19.

9. Tanner H, Boxall E, Osman H. Respiratory viral infections during the 2009-2010 winter season in Central England, UK: incidence and patterns of multiple virus co-infections. Eur $\mathbf{J}$ Clin Microbiol Infect Dis. 2012; 31(11): 3001- 3006.

10. Tanner H, Boxall E, Osman H. Respiratory viral infections during the 2009-2010 winter season in Central England, UK: incidence and patterns of multiple virus co-infections. Eur $\mathbf{J}$ Clin Microbiol Infect Dis. 2012; 31(11): 3001- 3006.

11. Bloom-Feshbach K, Alonso WJ, Charu V, et al. (2013) Latitudinal variations in seasonal activity of influenza and respiratory syncytial virus (RSV): a global comparative review. PLoS One. 8(2).

Future Researches: 
12. Tamerius JD, Shaman J, Alonso WJ, et al. (2013) Environmental predictors of seasonal influenza epidemics across temperate and tropical climates. PLoS Pathog. 9(3).

13. H. Bouguerra, M. Zorraga, M. Sakly, N.Abdeddaiem, R. Jaballah, H. Ouannane,E.Kobbi, A. Slim, B.A. Salah1, N. Ben Alaya. (2020) Seasonal influenza activity in Tunisia during 2016-2017, Journal of Infection and Public Health. 13; 457468.

14. Li Li, MMed, Yunning Liu, MD, Peng Wu, PhD, Zhibin Peng, MD . Xiling Wang, PhD, Tao Chen, MD . Nfluenza-associated excess respiratory mortality in China, 2010-15: a populationbased study, The Lancet Public Health. 4(9); 431-481.

15. Shweta Bansal, Babak Pourbohloul, Nathaniel Hupert, Bryan Grenfell, and Lauren Ancel Meyers. (2009) Version 2. PLoS Curr.

16. B. Pourbohloul, A. Ahued, B. Davoudi, R. Meza, L.A. Meyers, D.M. Skowronski, I. Villasenor, P. Kuri, F. Galvan, P. Cravioto, J. Trujillo, D.J. Earn, J. Dusho., D. Fisman, J. Edmunds, N. Hupert, S.V. Scarpino, D.M. Patrick, and R.C. Brunham. (2009) Initial human transmission dynamicsof the pandemic (H1N1) 2009 virus in North America. Influenza and Other Respiratory Viruses, 3 (5):215-222.

17. T.A. Reichart, N. Sugaya, D.S. Fedson, W.P. Glezen, and L. Simonsen. (2001) The Japanese experience with vaccinating school-children against influenza. N Engl J Med, 344:889-896.

18. A.S. Monto, J.S. Koopman, and I.M. Jr. Longini. (1985) The Tecumseh study of illness. XIII. Influenza infection and disease. Am J Epidemiol, 121:811-822.

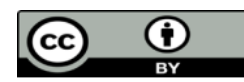

This work is licensed under Creative Commons Attribution 4.0 License

To Submit Your Article Click Here: Submit Article

DOI: $10.31579 / 2690-4861 / 109$

\author{
Ready to submit your research? Choose Auctores and benefit from: \\ * fast, convenient online submission \\ * rigorous peer review by experienced research in your field \\ * rapid publication on acceptance \\ * authors retain copyrights \\ * unique DOI for all articles \\ * immediate, unrestricted online access
}

At Auctores, research is always in progress.

Learn more www.auctoresonline.org/journals/international-journalof-clinical-case-reports-and-reviews 